\title{
A help or hindrance? Highly educated refugees' perceptions of the role of civic integration programmes in accessing the labour market in Oslo, Malmö and Munich
}

\author{
Katarina Mozetič (D)
}

${ }^{*}$ Correspondence:

katarina.mozetic@sosgeo.

uio.no

Department of Sociology

and Human Geography,

University of Oslo, Blindern,

Postboks 1096, 0317 Oslo,

Norway

\begin{abstract}
Research often focuses on individual-level factors shaping refugee labour market participation. Less research has been conducted on the implications of the roles of employers, integration programmes, migrant support organisations and similar. This article contributes to the literature by seeking to understand highly educated refugees' perceptions of how civic integration programmes shape opportunity structures for their labour market participation. It is particularly concerned with how the programmes' characteristics of malleability and comprehensiveness inform integration processes. Accordingly, the article analyses identification contestations that transpire within civic integration programmes, as perceived by the participants, and compares how these unfold in three different contexts. A total of 41 semi-structured interviews with highly educated refugees in Oslo, Malmö, and Munich were analysed. The findings suggest that the civic integration programmes were thought to either foster or hinder the participants'employment pathways depending on whether the participants were perceived as highly educated individuals or reduced to the general category of 'refugee.' The differences were traced back to each civic integration programme's capacity to provide malleable integration support, calling attention to the importance of the programmes' acknowledgment of refugees' heterogeneous needs and the pitfalls associated with undifferentiated refugee categorisation.
\end{abstract}

Keywords: Highly educated refugees, Labour market integration, Integration programme, Identity, Norway, Sweden, Germany

\section{Introduction}

In many European countries, refugees' participation in the labour market is a key concern. This participation constitutes an essential element of how refugees can contribute in the receiving society and is essential for the individual's economic independence, social inclusion and personal well-being (Ager \& Strang, 2008). However, compared to the majority population or other immigrant groups, refugees do not fare well on the labour market. They experience higher rates and longer periods of unemployment, and often end up in jobs beneath their qualifications (Lee et al., 2020).

(c) The Author(s) 2022. Open Access This article is licensed under a Creative Commons Attribution 4.0 International License, which permits use, sharing, adaptation, distribution and reproduction in any medium or format, as long as you give appropriate credit to the original author(s) and the source, provide a link to the Creative Commons licence, and indicate if changes were made. The images or other third party material in this article are included in the article's Creative Commons licence, unless indicated otherwise in a credit line to the material. If material is not included in the article's Creative Commons licence and your intended use is not permitted by statutory regulation or exceeds the permitted use, you will need to obtain permission directly from the copyright holder. To view a copy of this licence, visit http:// creativecommons.org/licenses/by/4.0/. 
Until recently, most academic attention has been paid to the individual-level factors affecting refugee labour market participation, such as refugees' demographic characteristics, motivations and attainments. Less scrutiny has been dedicated to the ways the receiving society shapes refugee employment, in particular, the organisational-level implications of, for instance, employers, integration programmes, newcomer support organisations [NSOs] and professional chambers (Lee et al., 2020; Maletzky de García, 2021; Phillimore, 2021).

This is problematic, given that, when perceived as a two-way process (Ager \& Strang, 2008), refugee labour market participation does not rest merely on refugees' efforts and capabilities but needs to be paired with an inclusive social fabric that provides acceptance, services and opportunities. Civic integration programmes [CIPs] represent one of the central pillars of refugee labour market integration support structures in European countries. They aim to assist refugees into employment through language training, employment counselling and referrals. They also provide refugees with resources such as information, skills, and social networks that are central for their labour market access (Lee et al., 2020). CIPs have been shown to have an important impact on refugee integration processes and outcomes (Phillimore, 2021). However, the evidence whether their impact is facilitating or hindering is mixed. Valenta and Bunar (2010) show that CIPs in Scandinavia improve the employability of participating refugees yet do not eliminate the employment inequality between the general population and refugees. Having analysed refugee women's encounters with the Swedish establishment programme, Spehar (2021) found that, in contrast, the refugee women did not find the assistance to be sufficiently quick or responsive to their needs. The perceived inadequate support was often seen as a critical factor hindering their labour market participation.

This article contributes to a richer understanding of the ways in which CIPs shape the labour market participation opportunity structures of highly educated refugees. ${ }^{1}$ With this aim, I analyse the identification contestations that transpire within CIPs as perceived by highly educated refugees and show how these inform refugee integration support. The article draws on material obtained through 41 semi-structured interviews with highly educated refugees in Oslo (Norway), Malmö (Sweden) and Munich (Germany). At the time of the interview, most interviewees had not lived in the destination country for longer than 3 years. Many had not entered into employment yet but were in the process of carving out their occupational trajectories while participating in CIPs, learning the language, and validating their qualifications. The interview material is rich with nuanced perceptions of the functioning of CIPs and the ways these give shape to participants' trajectories. Here, the refugees' occupational aspirations and understandings are the measure against which the integration progress and support are assessed. As such, the article departs from the more prevalent approach in research on the role of institutional and organisational factors for refugee employment that examines the effects of policy designs (see, e.g., Valenta \& Bunar, 2010). Moreover, it foregrounds the understanding of integration not as an outcome but rather as a process encompassing different challenges for the involved parties.

${ }^{1}$ Here, the term refers to individuals who were granted asylum and possess a higher education degree from another country. 
The comparative aspect of the study is important. The integration contexts in Oslo, Malmö and Munich were chosen because they differ according to their comprehensiveness (the scope of the encompassed provisions) and the extent of their malleability (the capacity to provide various types of support, depending on the participants' needs). Whereas the CIPs in Malmö display the most comprehensive and malleable framework, the provisions in Munich appear to be the most restricted and uniform, with the CIP in Oslo positioned somewhere between the two. The contrast between the refugees' perceptions of the CIPs among these diverging contexts allows me to delve into the ways CIPs' malleability and comprehensiveness inform opportunity structures that influence refugee labour market participation.

In the following section, I clarify the conceptual foundation this article rests upon and elaborate on how a focus on identification contestations that transpire within CIPs can further our understanding of which opportunity structures impede or facilitate the labour market participation of highly educated refugees. Thereafter, I outline how CIPs in Oslo, Malmö and Munich represent cases of different opportunity structures, diverging in their extents of malleability and comprehensiveness, and present the empirical study this article draws upon. In the subsequent empirical sections, I demonstrate how (mis)matches between refugees' identifications and perceived categorisations highlight opportunity structures that either hinder or foster highly educated refugees' employment trajectories and extricate how the malleability and comprehensiveness of CIPs underpin these processes. I conclude the article by pointing out the salience of the refugee categorisation within integration opportunity structures and the pitfalls connected to it.

\section{Integration opportunity structures as constituted by civic integration programmes}

Within migration studies, the concept of integration has been observed to have multiple and shifting meanings (Ager \& Strang, 2008). Its understandings are contextual and contested as they differ in time, space and between the various parties involved. Its ambiguity also derives from how the concept refers to numerous processes pertaining to an individual's life, including employment, housing, education, health and social networks. The vagueness of the integration concept stems, as argued by scholars critical of the concept (Favell, 2019; Korteweg, 2017; Rytter, 2019; Schinkel, 2018), from the careless adoption of policy and popular discourses in academic analysis.

The entanglement of policy and academic discourses pertaining to migrant integration is problematic for further reasons. Most relevant for this article is that academics often adopt a normative understanding of migrant settlement, where migrant practices and performance are compared with those of the majority population. Employed as a benchmark of integration, the majority population is imagined as 'a bloodless, unmovable, undifferentiated, static' (Schinkel, 2018, p. 7) yet also a harmonious whole that is acquitted of having any problems. The majority population is exempted from the integration equation. Conventional research, rather than conceiving it as a process pertaining to the society as a whole, renders migrants as problematic subjects and places the responsibility for integration on them. 
Here, in contrast, integration is conceived of as a two-way process (Ager \& Strang, 2008) that pertains not only to individuals but also requires accommodation on the part of the receiving society. To account for the mechanisms of inclusion and exclusion within the destination country, Phillimore (2021) suggests a focus on the so-called opportunity structures. She understands refugee integration opportunity structures as clusters of resources, arrangements and routes that either facilitate or undermine integration, such as xenophobia or foreign qualification recognition procedures. She delineates five opportunity structure domains-locality, discourse, relations, structure, and initiatives and support-and outlines how the places where refugees live, through their availability of housing, healthcare and employment, shape their integration processes and outcomes. The media and political discourses also play a central role in refugee integration, as they inform the emotional orientation of the receiving communities towards refugees, shaping the inclusiveness or discriminatory stance of interpersonal relations. Asylum, integration, family reunification and naturalisation policies have also been identified as key structural factors moulding the settlement of refugees in addition to the support services offered through integration programmes and support organisations.

Focusing on CIPs in three different contexts, this article is particularly interested in the opportunity structures that arise through the characteristics of support services. I argue that in order to explore the ways in which CIPs provide integration-impeding or integration-furthering opportunities, it is useful to highlight how the participants perceive identification contestation processes that transpire within such programmes.

\section{Civic integration programmes as loci of identification contestations}

Migration and flight, in particular, represent life disjunctures that bring substantial changes, including the transformation of one's sense of self. Fleeing one's home country often entails not only the loss of a homeland, family and friends, familiar lives and jobs, but also a sense of who one is and where one belongs in the social fabric (Wehrle et al., 2018). Highly educated refugees experience losses of both social and occupational status (Colic-Peisker \& Tilbury, 2006). In the destination country, they have to figure out who they are and who they want to be.

This article takes a dynamic view on identities, where identities are not understood as essential entities that are simply chosen or ascribed but rather reproduced through a dialectic interplay between internal self-identifications and external categorisations (Brubaker \& Cooper, 2000; Jenkins, 2000, 2008; Zetter, 1991). Indeed, the concepts of self-identification and categorisation, in addition to self-understanding and labels, provide useful heuristic tools to disentangle the forces encompassed within the identification contestation processes. Self-identification refers to the contextual act of characterising and positioning oneself in relation to others, and it can be either categorical or relational. In contrast, categorisations refer to identifications imposed on individuals by others. They can be performed either by specific actors, for example, individuals or political bodies, or occur by means of, for instance, public discourses. Acts of self-identification are closely connected to a person's own sense of themselves (i.e. selfunderstanding) which involves one's idea of who one is and of one's social location, and therefore, how one should be prepared to act. Concurrently, categorisations always come hand in glove with the processes of labelling. Labels can be conceived of as marks of 
categorisations; they represent a set of meanings assigned to the bearer of the label associated with a given category.

In the destination country, highly educated refugees typically seek to find employment that is commensurate to their educational level and occupational experience. However, the pursuit of employment is not only a question of economic self-sufficiency but is also closely tied to the question of who one is and who one wants to be. Highly educated refugees' occupational aspirations are informed, among others, by their self-perceptions as motivated, ambitious, work-loving individuals eager to contribute to the receiving society (Mozetič, 2021; Willott \& Stevenson, 2013). When seeking to attain the desired occupational goals, highly educated refugees encounter numerous hurdles. Whereas the devaluation of their educational credentials and work experience has been observed as one of the most notable challenges (Khan-Gökkaya \& Mösko, 2021), many scholars also foreground the impeding effect of the imposed refugee categorisation. In his article on Syrian refugee artists in Austria, Parzer (2021) shows how being categorised as a refugee, by bureaucratic institutions and in everyday encounters with the majority population, affects artists' practices, and their positioning and self-representation in cultural markets. Being seen as refugees creates the expectation to speak for the refugee community, rather than to express themselves beyond their refugee self. Showing how Dutch integration programme represents a core practice of Othering migrants like refugees, Blankvoort et al. (2021) claim that the programme not only fails to contribute to the integration of its new members, but further perpetuates their marginalisation.

The refugee label is shifting and dynamic, assuming various meanings. Refugee categorisation can be seen as a "privileged" one (Cole, 2018) for granting access to international protection and integration support services (Ludwig, 2016; Mozetič, 2018). Refugees are occasionally depicted as defiers of authoritarian regimes and individuals eager to seize the given second chance at life (Haines \& Rosenblum, 2010). The refugee label is, however, also a source of stigmatisation and marginalisation. Often, refugees are labelled as helpless, desperate, and suffering victims without agency, in addition to being an economic burden and a potential security threat (Gupte \& Mehta, 2007; Ludwig, 2016). As such, the refugee label is not neutral but rather conveys a set of judgements and expectations, acting as a vital element that positions groups within symbolic orders (Zetter, 1991).

Given that CIPs are affiliated with states and public institutions, the categorisations and labels that arise from within them can be distinguished from those used by individuals, in that they are formalised. Their apparent objectivity, however, often obscures the power dynamics comprised within them. They have the capacity to dictate, cement and alter how we think of and engage with the world around us (Moncrieffe, 2007). Through possessing the power "to state what is what and who is who" (Brubaker \& Cooper, 2000, p. 15) and to impose such categorisations and labels upon others, the state as well as other public institutions represent some of the most paramount agents of the construction of social reality. While state categorisations and labels can be contested or changed (Crawley \& Skleparis, 2018), their capacity to shape how people are regarded and treated, to determine which issues are presented and how they are to be thought of cannot be denied. 
As such, the categorisations refugees are (or perceive themselves to be) classified within have real-life consequences for them, affecting how they behave and are treated, constrained and assisted. CIPs shape refugees' understanding of their occupational opportunities, education and career pathways. Depending on the ways the perceived categorisations and self-ascribed identifications play out within these programmes, refugees not only experience diverse identification contestations but also foster different integration responses that inform their labour market trajectories. Identification contestations that refugees perceive to transpire within CIPs thus create specific opportunity structures which either curb or advance refugees' efforts to attain the set occupational goals.

\section{Malleability and comprehensiveness of civic integration programmes}

This section presents and compares the CIPs in which the interviewed highly educated refugees in Oslo, Malmö and Munich were participants. Particular attention is given to state integration programmes for refugees and tailored qualification programmes for migrants with specific occupational backgrounds. The distinctions between the three contexts lie along two dimensions-the malleability and comprehensiveness of the CIPs. In both dimensions, the integration programmes in Malmö and Munich stand in opposition to each other, while the Oslo programme can be placed somewhere in between them.

The malleability of the CIPs refers to their capacity to provide various types of support, depending on the participants' needs. The capability to address the programme participants' heterogeneous needs is considered central to the success of these programmes (Spehar, 2021). The comprehensiveness of the CIPs refers to the scope of the encompassed provisions (i.e. whether they include, for instance, employment guidance or not). It has been noted that the lack of integration assistance can lead to further hardship for the refugee population, but it also has the potential to strengthen a person's agency and adaptability (Korac, 2003).

The CIPs in Malmö and its surroundings can be characterised as the most comprehensive and malleable of the three contexts. The core of CIPs in Sweden represents the establishment programme (etableringsprogrammet), which consists of orientation and language courses. Over the duration of 2 years, the programme enables refugees to reach solid Swedish language proficiency, qualifying most highly educated refugees to re-enter university education, to validate their professional qualifications as well as to apply for internships and positions that would jumpstart their careers. In addition to the language and orientation courses, the establishment programme offers specific measures targeting refugees' labour market participation. The major responsibility for the implementation of the programme lies with the Swedish public employment services [PES] (Arbetsförmedlingen). The labour market integration measures consist primarily of employment guidance by PES case officers who, on the basis of the individual's occupational background and aspirations, are responsible for creating an employment plan and assisting them in validating their qualifications and finding job placements. In addition to the establishment programme, Sweden has created a number of tailored qualification programmes for migrants with specific occupational backgrounds. In general, these programmes offer parallel mapping and the validation 
of qualifications plus occupation-related training and language courses. They enable refugees with certain backgrounds such as medicine, teaching and IT to quickly reenter their occupations. A number of such programmes were accessible to the interviewees in Malmö: the fast-track (snabbspåret) and the short route (korta vägen) programmes, and a programme in web and system development.

In contrast to Malmö, the German integration course (Integrationskurs) can be characterised as the least comprehensive and malleable. Similar to the establishment programme, the integration course offers language and orientation courses, but lacks measures aimed specifically at refugee employment. Rather than implemented by the PES, as in the case of Sweden, the integration course is coordinated by the German Federal Office for Migration and Refugees [BAMF] and implemented by certified course providers like adult education centres (Volkshochschule). The German PES (Jobcenter) offers unemployed refugees access to mainstream employment measures, but these are not a part of the integration course and instead run parallel to it. This is problematic because not all refugees are aware of the guidance provided by the jobcentres and even less make use of it (Brücker et al., 2016, p. 10). The integration course is also limited in its duration. Unlike the 2-year establishment programme, the integration course finishes after the participant reaches the language proficiency equivalent to the B1 level of the Common European Framework of Reference for Languages [CEFRL]. This hinders refugees from accessing higher education or validating their qualifications, as these often require the $\mathrm{C} 1$ level. Lastly, highly educated refugees in Munich did not have access to any qualification programmes tailored for highly educated migrants.

The Norwegian introduction programme (introduksjonprogram) can be positioned between those in Malmö and Munich when it comes to malleability and comprehensiveness. The structure and organisation of the programme closely resembles the Swedish establishment programme. It is also implemented by the national PES (Arbeids- og velferdsforvaltningen-[NAV]) and lasts 2 years. In addition to the language and orientation courses, it includes labour market integration measures consisting of work placements (those that emphasise language training and those that provide the opportunity to acquire occupation-related skills) and guidance by PES case officers. However, in contrast to the Swedish case and closer to the German case, highly educated refugees in Oslo did not have the possibility of participating in programmes tailored specifically for migrants in particular occupations. ${ }^{2}$

\footnotetext{
${ }^{2}$ Despite that fast-track programmes (hurtigspor) in Norway and job-related language courses in Germany are available, none of the interviewed highly educated refugees living in Oslo and Munich took part or were aware of them. This may be due to the programmes not being offered where the interviewees lived, or, as in the case of the Norwegian fast-track programmes, they did not exist at the time of this study's fieldwork. Whereas the sampling technique employed in this research undoubtedly contributed to the high number of the interviewees in Sweden participating in special integration programmes, their prominence within the Swedish integration landscape cannot be denied.
} 


\section{Methods and material}

The article draws on semi-structured interviews with 41 highly educated refugees living in Norway, Sweden and Germany. The sample includes individuals who originally came from a country in the Greater Middle East, possess a completed university degree from a non-EU country, and were granted asylum ${ }^{3}$ in the destination country.

The sample consists of individuals who lived in either Oslo, Malmö or Munich, or their surroundings. A total of 11 lived in Norway, 15 in Sweden and 15 in Germany. The majority of the interviewees (33) came from Syria, five from Afghanistan, one from Yemen, Iraq and Palestine respectively. The interviewees were between 24 and 56 years old (average age was 35 years). The majority were in their 30s (21), and the rest were in their $40 \mathrm{~s}$ and 20s. One was above age 50. The sample includes 31 male and 10 female interviewees. The participants had lived in the destination country between 10 months and 5 years $^{4}$ (average time since arrival was 27 months). A total of 16 individuals had degrees within regulated occupations: 11 were medical doctors and dentists, four were teachers, and one was a pharmacist. As for the rest, eight interviewees were educated in engineering and eight in IT, four in business administration, two in English literature and four had other degrees. All were educated in the Greater Middle East, with the exception of two who studied in other Asian countries and one who graduated in the USA. Four research participants had over 20 years of work experience, 15 had between 10 and 20 years' experience, 17 had less than 10 years' experience, and four had none.

All interviews were conducted by the author between September 2016 and July 2017. The interviewees were recruited through personal contacts, integration programmes, NSOs and events for refugee academics. Individuals were also invited to participate in the study through mailing lists and social media.

The interviews took place when and where it was most convenient for the interviewees (cafés, the interviewee's home, the workplace). The interviews resembled life-course interviews. They followed the individual's educational and occupational trajectories, their asylum-seeking processes, initial time in the destination country, and future plans. The interview guide focused specifically on educational and occupational experiences and considerations as well as experiences pertaining to the CIPs, asylum, and qualifications validation procedures. This allowed me to map out the interviewees' educational, occupational and migration trajectories, and to document their subjective perceptions of these. The interviews lasted between $30 \mathrm{~min}$ and three hours (average length being $90 \mathrm{~min}$ ). With the exception of two (following the request of the interviewees), all interviews were audio-recorded. The interviews were conducted in English, Norwegian, Swedish or German, depending on the interviewee's language preference. The interviewees were conversant, many even proficient, in the chosen language, having principally no difficulties understanding the questions or expressing their ideas. The interviews were transcribed in the language of the interview and translated into English only when directly quoted in a publication.

\footnotetext{
${ }^{3}$ Given that one research participant's wife (of Syrian origin) has Swedish citizenship, one man in Sweden received a residence permit as a family member. He is nevertheless included in the sample because he and his wife lived in Syria before deciding to leave the country at the end of 2013 due to the civil war.

${ }^{4}$ One interviewee lived in Sweden for over 9 years, but the first 6 years were without a residence permit.
} 
Initially, I analysed the material using descriptive and dramaturgical coding (Saldaña, 2009), which allowed me to gain a general sense of the interviewees' occupational objectives, obstacles encountered along the way, strategies to pursue goals, and attitudes towards the settings they found themselves in. Whereas these first rounds of coding remained close to the terms used by the interviewees, I subsequently undertook the iterative process of converging the codes with theoretical concepts and frameworks. Whereas a bulge of material focused on the barriers linked to the interviewees' lack of relevant human, cultural and social resources, a salient portion dealt with identification contestations. Of particular interest were those that transpired within the CIPs, compelling me to further explore them in order to comprehend their formative character.

The following sections present the empirical findings, which show the perceived identification contestations and how these inform interviewees' integration trajectories. For the sake of clarity, the comparative dimension of the findings is not taken up here but is instead elaborated on in the subsequent section.

\section{Occupational self-identifications, divergent and convergent categorisations}

In the context of CIPs, the interviewed highly educated refugees mainly identified themselves as highly educated persons (within specific occupational fields). Rather than participating in these measures as refugees trying to enter some kind of employment, the interviewees hoped that the programmes would help them to obtain employment according to their educational and occupational background. Referring to a language course taken in his introduction programme in a town outside Oslo, Yasser, ${ }^{5}$ a Syrian medical doctor, negatively evaluated the course from his position as a medical doctor: "But when you know everything about me, you know that I'm a doctor. It is serious. So, you send me to some kind of experimental course? It's a fake course." Indeed, the majority of the interviewees aspired to find employment according to their educational and occupational background. Yasser claimed he would not be able to recognise himself if he changed his occupation: "I cannot work as a sociologist. And I cannot work as a lawyer. I am not good at that. If I work in another occupation, I cannot recognise myself. (...) For me, it is a better solution to go to another country than to change my occupation."

However, as the following two sections elucidate, it was predominantly the interviewees in Malmö who felt that their self-identification as highly qualified individuals resonated with the way they felt they were perceived and treated within the CIPs. The majority of the interviewees in Oslo and Munich felt, in contrast, that the categorisation they were ascribed to was that of a refugee which overshadowed their educational and occupational selves.

\section{Perception mismatches}

The interviewees in Oslo and Munich predominantly thought that the CIPs were to a great extent created for refugees as a standardised category. Many perceived that the programmes failed to acknowledge the varying educational and occupational backgrounds they possess. When discussing the Norwegian introduction programme, Hanin,

\footnotetext{
${ }^{5}$ All names used in the article are pseudonyms.
} 
a Syrian accountant, observed that it was designed to deal with refugees as a "fixed mass" rather than individuals with particular pasts:

I don't think they deal with the refugees as individuals. They deal with them like they are some kind of a fixed mass of something, not of people, a fixed mass of something, just to get rid of it somehow. They think the goal they have to achieve is to send them to some city without looking at their experiences, at their work before, at their education, nobody cares about that. They don't ask you about your CV. They don't ask you really what work you did before.

Many interviewees experienced the reduction to their refugee status as a nullification of their occupational biographies and skills, as if the refugee categorisation overshadowed their occupational selves. Wehrle et al. (2018, p. 98) observe that the stories of loss that are associated with being a refugee do not necessarily cease in the destination country:

Rather, the various integration barriers to work and society (...) may come to threaten some of the last resources these people bring with them - their identities - and with that, their fundamental human needs for a sense of worth, distinctiveness, continuity, and control over who they are in general and in their vocation in particular.

The refugee categorisation, however, did not merely discredit interviewees' existing identifications, but also imposed new, pejorative ones upon them (Wehrle et al., 2018). The perceived refugee categorisation brought with it, according to many, the disparaging label of refugees as "stupid" and "lazy" individuals who "don't want to learn" and require merely basic life provisions such as security and financial support. The assigned characteristics were often in stark contrast to how highly educated refugees understood themselves. They mainly saw themselves as resourceful individuals who are motivated, ambitious and eager to develop, and to whom meaningful work is of central value. Rather than accepting the ascribed role of that of a receiver, they saw themselves as contributors in the destination country. Farhad, an Afghani business administrator in Munich, explains: "They are providing us [with] money. What should we do with this money? We don't need money. We want to improve! We want to make our career here once again!".

\section{Being seen for what they know}

The majority of the interviewees in Malmö had a different story to tell. Many felt that the CIPs acknowledged their occupational identity, recognised their capabilities, and regarded them as ambitious and hard-working.

In contrast to the interviewees in Oslo and Munich, who often perceived the PES case officers as being dismissive of their professional selves, many interviewees in Malmö felt that the PES case officers acknowledged their occupational backgrounds and goals. The perceived affirmations of the interviewees' own self-understandings were greatly appreciated, as they gave them the confidence to pursue their occupational ambitions. A Syrian electrical engineer living in Malmö, Firas felt that the assured and positive attitude of his PES case officer towards him as an electrical engineers instilled him with a sense that his life and priorities matter, and also with hope: 
She [his PES case officer] gave me a lot of hope that we can take a place in society and that there is a real need for us, especially engineers. There are companies that need energy engineers, that we are welcome in society, that we can take a place (...) She talks about internships for foreign electrical engineers like me. She talks about my case. But she smiles, I can remember very well. It was really, really important for me because for the first time, I meet someone from the community, and we talk about something serious. We plan for my life, we talk about school, about internship, about jobs. It felt very good. She gave me a lot of hope. She spoke with faith, a lot of confidence: 'You will get an internship. You will get a job.'

As he explained later, the encouragement motivated him and helped him re-establish his professional life in Sweden.

In addition to their encounters with the PES case officers, many interviewees in Malmö mentioned tailored qualification programmes as spaces where their occupational identities received affirmation. The participants of those programmes unanimously felt that their occupational pasts and aspirations were recognised there. Mahwash, an Afghani medical doctor in Sweden, was satisfied with her participation in the short route programme because she felt that all the participants were on the same level: "All participants are nurses, medical doctors, engineers. What we talk about-it is our world. In the language course [encompassed within the establishment programme], I was there with youngsters."

\section{Paving the way forward}

The (mis)match between highly educated refugees' self-identifications and self-understanding, and the way they feel they are categorised and labelled has important repercussions. The (dis)accord can not only give rise to feelings of frustration and passivity but also hope and motivation, shaping refugee employment trajectories. Refugees are often highly motivated to find work, yet the lack of needs-based assistance, poor economic conditions, and high barriers to employment can eventually lead to demotivation, lower self-efficacy, and prompt passivity (Lee et al., 2020; Rytter, 2018; Willott \& Stevenson, 2013).

As elaborated in the subsequent sections, the (dis)harmonious identification and categorisation processes have further impacts. The acknowledgment of interviewees' occupational selves within CIPs as experienced by many interviewees in Malmö implied the acknowledgment of their occupational capabilities and goals, leading to integration opportunities that were conducive to their aspired labour market trajectories. In contrast, the friction between occupational self-identification and refugee categorisation, as often felt by the interviewees in Oslo and Munich, brought with them integration support that was not conducive to their employment plans. The oversimplified refugee categorisation and label were perceived as overshadowing their occupational identifications and as framing them as "a monolithic mass" (Ludwig, 2016, p. 7) with assumed needs that were in disaccord with the actual needs of interviewees. Consequently, the support encompassed within CIPs in Oslo and Munich was often deemed irrelevant, making the interviewees embark on the occupational trajectories on their own, or it appeared to direct them towards underemployment. 


\section{Towards underemployment}

Many interviewees in Oslo and Munich were under the impression that the CIPs did not allow them to think big. This led them to feel that their occupational dreams were curtailed, and instead, that they were redirected towards the more attainable, shortterm goal of completing the CIP. They also reported that the received support hardly surpassed that of financial assistance and basic language training. The elementary nature of CIPs' provisions is understandable when we consider that, among others, the programmes' aim is for fast refugee employment. This is problematic because refugees are often expected to find whatever kind of employment, not necessarily employment commensurate with their occupational background. This can be counterproductive to their integration, as it creates frustration and apathy (Rytter, 2018).

Indeed, the interviewees in Oslo and Munich often felt that the CIPs were not able to cater to their aspiration to enter employment in line with their qualifications, but instead the CIPs provided uniform support regardless of the refugees' occupational background. Several interviewees in Munich raised criticism about how the integration course ends once the participant reaches language proficiency equivalent to the B1 level of the CEFRL. This represented a serious hindrance for highly educated refugees who hoped to ameliorate their chances on the German labour market by enrolling at a university which requires a higher level of language skill. Moreover, many felt that their PES case officers did not recognise their needs as qualified individuals, instead offering support that was not conducive to their aspirations. For instance, most interviewees in Oslo thought that their PES case officers did not help them obtain occupation-related internships but could provide them with language-training internships in day-care centres, elderly care homes and supermarkets, which were unrelated to the interviewees' occupations. The only internship that Salim, a Syrian medical specialist, was offered by his PES case officer was at an elderly care home or a supermarket:

They [his PES case officer] said, 'You have the opportunity to practice in elderly care homes.' I said, 'Yes, but elderly care homes have nothing to do with medicine. Elderly care homes are for nurses or healthcare workers, not for me.' They said, 'Yes, but you can practice Norwegian. You can talk to people there, and you get more knowledge in Norwegian'. I said, 'Yes, but I know that many people who live in elderly care homes are demented. It's very difficult to talk to them or they talk very strange, or...'

(...) They said, 'Okay, but that's what we can offer you. No more. Or you have KIWI [laughs] and Coop [names of two supermarket chains].'

Salim was not the only one who mentioned that the PES offered language internships at a supermarket like KIWI. They felt that when the PES case officers "think of a refugee, they think of KIWI" (Nabil, a Syrian dentist from Oslo).

Taken together, many interviewees in Oslo and Munich felt that the integration programmes dragged them away from an employment trajectory corresponding to their qualifications and instead directed them towards underemployment. As Saleh, a Syrian mechanical engineer in Munich, observed: "To be honest, sometimes you feel that the system pushed you to or forced you to work in some [low-skilled] places." 


\section{Left to fend for themselves}

Many interviewees in Oslo and Munich felt that the support catering past their needs was hardly better than having no support at all. Hanin, a Syrian accountant living in Oslo, claimed that, even though refugees seemingly receive a lot of help, they in fact do not because most of it does not effectively address the needs of highly educated:

You think when you read the newspaper, [that] everybody is helping us somehow. But we are not getting any help. They have to stop writing that everybody is helping us, everybody is giving us money, everybody is doing the impossible things to help us to continue. Stop saying that. (...) You have to choose and say, 'It's not our job to help anyone.' Then you will understand nobody is going to help. Or say, 'We are helping these people' and [than actually] help me then. You have to help them then in an efficient way.

The comparison of highly educated refugees' experiences with CIPs in Oslo and Munich is important, particularly in relation to the employment guidance received through PESs. Whereas the interviewees in Munich were subject to either mainstream employment guidance or none at all, the employment guidance for those in Oslo was an integral part of the introduction programme, and yet, it was perceived as seldom tailored to the individual's needs. References to PES guidance among the interviewees in Munich were predominantly either non-existent or negligible. The absence of guidance made many interviewees rely on themselves when seeking internships, programmes and courses that would advance their occupational trajectories. Moreover, they sought information and assistance through their personal acquaintances and local NSOs (Gebhardt, 2016; Hillmann \& Toğral Koca, 2021). Korac (2003) shows that the lack of integration assistance forces refugees to rely on their own resources when reconstructing their lives. While the interviewed highly educated refugees did not have to rely on their social networks in order to survive, as did many ex-Yugoslavian refugees in Rome, the perception of having to depend on themselves finds attestation also within this study.

I claim, however, that it was not only the lack of employment guidance that made the interviewees feel they were left to carve out their occupational trajectories themselves but also the non-existence of tailored, needs-based guidance. The interviewees in Oslo, one after another, recounted how they had to "work alone" (Yasser) to advance along the set employment trajectory or to receive help from their social contacts. "The system can't help you. You only can count on who do you know. And how can they help. And that's all", reflected Hanin. Mazen, a Syrian civil engineer, felt that the Norwegian introduction programme left it up to the highly educated refugees themselves to find employment: "NAV [Norwegian PES] can't do anything. They do a lot for society, but for refugees who have good education, they always say: 'You have to find yourself, you have to travel yourself.' Indeed, the internship he did at a consulting engineering group was found and arranged by himself without the assistance of his PES case officer. As a matter of fact, Mazen felt that the completion of the introduction programme made him "free" to finally pursue his own occupational interests, invoking the lock-in effect CIPs have been criticised for (Gebhardt, 2016). A similar observation is made by Nardon et al. (2021) who analyse the role of NSOs in refugee employment integration. They show that refugees who did not accept NSOs' recommendation to embark on a career path 
incommensurate with their occupational background and experiences often disengaged from NSOs' services and were left to carve their labour market trajectories on their own.

\section{Furthering opportunity structures}

In contrast, many interviewees in Malmö perceived that the received support catered to their needs as highly educated individuals, offering them opportunities that fostered the pursuit of their aspired labour market trajectories. Many felt that their PES case officers went to great lengths to help find occupation-related internships and to direct them to tailored qualification programmes commensurate to their occupations. As such, the PES case officers represent not only markers of facilitating opportunity structures but also the means of accessing additional furthering opportunities.

Indeed, occupation-related internships and tailored qualification programmes were seen as particularly conducive to their aspired occupational trajectories. The interviewees felt enabled to tap into existing occupational skills, obtain occupational language skills, and foster social networks within their occupational fields, all of which were considered critical to their employment trajectories. Moreover, the tailored qualification programmes were appreciated for their support with licensure and for accelerating the labour market re-entry.

\section{Fleshing out the comparisons}

The following comparison is not meant to be an evaluation of the CIPs in Oslo, Malmö and Munich. Rather, employing the presented programmes as cases of CIPs with different extents of malleability and comprehensiveness, it interrogates how these CIPs' characteristics shape highly educated refugees' opportunities to pursue their occupational goals.

The comparison demonstrates the significance of CIPs' malleability in creating integration opportunity structures that advance highly educated refugees' employment trajectories. As perceived by the highly educated refugees in Oslo and Munich, the less malleable CIPs often ceased to advance support commensurate to their needs. The interviewees often felt that the programmes directed them towards underemployment, making them rely on themselves to pursue their desired trajectories. In contrast, highly educated refugees felt that the more malleable CIPs in Malmö, by acknowledging individuals' educational and occupational backgrounds, created opportunities for them to pursue their employment ambitions.

Not all research pertaining to the Swedish establishment programme documents its ability to provide needs-based assistance (see, e.g., Bucken-Knapp et al., 2018; Gebhardt, 2016; Spehar, 2021). As elaborated in a later section, the implementation of integration provisions does not necessarily follow their design, and refugees' perceptions of the measures are coloured by their encounters with street-level bureaucrats. A possible explanation for the dominance of perceptions documenting individually tailored support lies in the specific local structure of integration programmes in Malmö and its surroundings, and the sample of interviewees. Ten out of 15 interviewees in Sweden had backgrounds in fields (medicine, teaching and IT) in which there existed tailored qualification programmes. These programmes aided the interviewees in pursuing their 
occupational aspirations and provided the PES case officers with opportunities for relevant referrals.

This brings me to the second point of discussion. CIPs' potential for creating integration opportunity structures for highly educated refugees stems not only from their design but also their implementation. Whereas the Norwegian integration programme and the Swedish establishment programme both promise individually tailored measures (occupation-related internships and PES case officers' employment guidance), highly educated refugees' perceptions of support in Oslo seldom resembled those of interviewees in Malmö. In fact, they were often aligned with more critical and dissatisfied accounts of interviewees in Munich. The presented empirical findings indicate that the PES case officers may represent the crux of this puzzle. Through their capacity to acknowledge the participants' occupational background and aspirations, the case officers determined what type of employment guidance and referrals were needed to further integration support. They acted as the markers and means of facilitating, or else impeding, opportunity structures.

This is not to say that the PES case officers single-handedly determined the refugees' employment trajectories. Their guidance and support depend on adopted categorisations (Grip, 2020) and the amount of relevant information and knowledge (BuckenKnapp et al., 2018). Their work, however, always transpires within larger socio-political frameworks that depend on specific policy contexts, localities with a set availability of relevant referrals (Khan-Gökkaya \& Mösko, 2021; Lillevik \& Tyldum, 2018), and historical events like the 2015 'refugee management crisis' (Brekke \& Staver, 2018). That said, the perceptions of highly educated refugees document PES case officers' central role in the everyday fostering or impeding of integration opportunities, echoing the idea that policy is made not only through political decision-making but also through the ongoing practice of individual case workers (Spehar, 2021). Although the comparison across different contexts necessarily amplifies the predominant patterns of refugee perceptions within each setting, this does not imply that there was no variation. Facilitating and impeding opportunity structures were reported across all three contexts, regardless of how malleable the CIPs are designed to be.

Lastly, the comparison not only shows how the lack of integration opportunity structures prompted the interviewees to rely on themselves to pursue their occupational aspirations but also highlights how the existing structures that hinder these aspirations do so. Causing refugee employability to be dependent on the refugees' own resourcefulness and social networks can add to their vulnerability, delaying their labour market re-entry and casting them into economic difficulties. Through its potential to create spaces for independence, it can, however, also activate their social networks, foster self-sufficiency and amplify their agency, ingenuity and adaptability (Gupte \& Mehta, 2007; Korac, 2003; Mozetič, 2021). Despite these potentially favourable outcomes, refugee independence in their employment pursuit is problematic, as it absolves the destination country from the responsibility of refugee integration and shoulders it solely on the refugees themselves. 


\section{Concluding remarks}

The article demonstrates the importance of paying attention to the receiving end of the integration equation (i.e. the ways highly educated refugees perceive the role of CIPs in fostering or impeding their integration pathways). Despite their proactivity, motivation, and eagerness to obtain the necessary resources to pursue their occupational goals, only a fraction of highly educated refugees felt that the CIPs promoted their desired trajectory. When the refugee professionals felt that they were seen and treated as highly educated individuals, they thought that the guidance and support of the CIPs formed an opportunity structure that promoted their employment participation. In contrast, many other perceived that the CIPs approached them as an unvaried mass of refugees, neglecting their occupational history and capacities, and failing to acknowledge the diversity of their needs. They found that these CIPs largely provided opportunity structures that hindered the attainment of their occupational aspirations, and in their view, the provided support had the potential to lead to their underemployment.

The differences in perception regarding the (un)suitability of the provided opportunity structures can be traced back to the malleability of the CIPs. This falls in line with previous research which stresses the importance of integration measures' capacity to recognise and be responsive to the heterogeneity of the refugee population and their needs, whether it be according to age, gender, or, as shown here, educational and occupational background. Indeed, as the highly educated refugees' encounters with the Norwegian introduction programme indicated, the comprehensiveness of the CIPs was considered of little importance if the support is not tailored to the participants' needs. The provided opportunity structures are seen as irrelevant to the individuals' employment goals, causing them to disengage with the offered support and rely on themselves instead. In that respect, comprehensive, yet uniform programmes foster integration strategies similar to contexts with absent support provisions.

In light of this, the article highlights the states' complacency in refugee labour market participation. It testifies to the enduring salience of the refugee categorisation and label, and pitfalls associated with them. The failure to adequately understand the diverse capacities and needs of refugees has been shown to affect the provision of asylum protection (Crawley \& Skleparis, 2018), humanitarian aid in refugee camps (Gupte \& Mehta, 2007; Zetter, 1991), and, as demonstrated in this article, their settlement. This is problematic, as it not only negatively impacts individuals' experiences of flight and settlement but also hinders the creation of receiving-society opportunity structures that would facilitate integration rather than obstruct it. Resting on an such oversimplified categorisation that does not reflect the lived realities of individuals, the array of measures in place, such as the CIPs, that are intended to foster refugee integration, perpetuate their marginalisation instead.

Abbreviations

BAMF: German Federal Office for Migration and Refugees; CEFRL: Common European Framework of Reference for Languages; CIP: Civic integration programme; NAV: Norwegian public employment services; NSO: Newcomer support organisation; PES: Public employment services.

Acknowledgements

I would like to thank the research participants who contributed to this study with their stories and perspectives. Moreover, I am indebted to many people who read and commented on this paper. In particular, I would like to thank Anniken 
Hagelund and Magdalena Nowicka as well as the anonymous reviewers for their thorough, critical, and very useful comments on this manuscript.

\section{Authors' contributions}

The author read and approved the final manuscript.

\section{Funding}

Not applicable.

Availability of data and materials

More detailed information on the material is available from the author upon reasonable request. Due to issues of confidentiality, this excludes full interviews and transcriptions.

\section{Declarations}

\section{Ethical approval}

The study was granted ethical approval by the Norwegian Centre for Research Data and the Regional Ethics Review Board in Lund, Sweden.

\section{Competing interests}

The author declares that she has no competing interests.

Received: 19 April 2021 Accepted: 19 January 2022

Published online: 11 February 2022

\section{References}

Ager, A., \& Strang, A. (2008). Understanding integration: A conceptual framework. Journal of Refugee Studies, 21, $166-191$. https://doi.org/10.1093/jrs/fen016.

Blankvoort, N., van Hartingsveldt, M., Laliberte Rudman, D., \& Krumeich, A. (2021). Decolonising civic integration: A critical analysis of texts used in Dutch civic integration programmes. Journal of Ethnic and Migration Studies, 47, 3511-3530. https://doi.org/10.1080/1369183X.2021.1893668.

Brekke, J.-P., \& Staver, A. (2018). The renationalisation of migration policies in times of crisis: The case of Norway. Journal of Ethnic and Migration Studies, 44, 2163-2181. https://doi.org/10.1080/1369183X.2018.1433026.

Brubaker, R., \& Cooper, F. (2000). Beyond "identity." Theory and Society, 29(1), 1-47.

Brücker, H., Rother, N., Schupp, J., Babka von Gostomski, C., Böhm, A., et al. (2016). IAB-BAMF-SOEP-Befragung von Geflüchteten: Flucht, Ankunft in Deutschland und erste Schritte der Integration. BAMF-Kurzanalyse. Nürnberg: BAMF.

Bucken-Knapp, G., Fakih, Z., \& Spehar, A. (2018). Talking about integration: The voices of Syrian refugees taking part in introduction programmes for integration into Swedish society. International Migration, 57, 221-234. https://doi.org/ 10.1111/imig.12440

Cole, G. (2018). Beyond labelling: Rethinking the role and value of the refugee 'label'through semiotics. Journal of Refugee Studies, 31, 1-21. https://doi.org/10.1093/jrs/fex021.

Colic-Peisker, V., \& Tilbury, F. (2006). Employment niches for recent refugees: Segmented labour market in twenty-first century Australia. Journal of Refugee Studies, 19, 203-229. https://doi.org/10.1093/jrs/fej016.

Crawley, H., \& Skleparis, D. (2018). Refugees, migrants, neither, both: Categorical fetishism and the politics of bounding in Europe's 'migration crisis.' Journal of Ethnic and Migration Studies, 44, 48-64. https://doi.org/10.1080/1369183X.2017. 1348224.

Favell, A. (2019). Integration: Twelve propositions after Schinkel. Comparative Migration Studies, 7, 1-10. https://doi.org/10. 1186/s40878-019-0125-7.

Gebhardt, D. (2016). When the state takes over: Civic integration programmes and the role of cities in immigrant integration. Journal of Ethnic and Migration Studies, 42, 742-758. https://doi.org/10.1080/1369183X.2015.1111132.

Grip, L. (2020). Knocking on the doors of integration: Swedish integration policy and the production of a national space. Journal of International Migration and Integration, 21, 861-877. https://doi.org/10.1007/s12134-019-00691-y.

Gupte, J., \& Mehta, L. (2007). Disjunctures in labelling refugees and oustees. In J. Moncrieffe \& R. Eyben (Eds.), The power of labelling: How people are categorized and why it matters (pp. 64-79). London: Earthscan.

Haines, D. W., \& Rosenblum, K. E. (2010). Perfectly American: Constructing the refugee experience. Journal of Ethnic and Migration Studies, 36, 391-406. https://doi.org/10.1080/13691830903358445.

Hillmann, F., \&Toğral Koca, B. (2021). "By women, for women, and with women": On the integration of highly qualified female refugees into the labour markets of Berlin and Brandenburg. Comparative Migration Studies, 9, 1-18. https:// doi.org/10.1186/s40878-020-00211-3.

Jenkins, R. (2000). Categorization: Identity, social process and epistemology. Current Sociology, 48(3), 7-25.

Jenkins, R. (2008). Social identity (3rd ed.). Abingdon: Routledge.

Khan-Gökkaya, S., \& Mösko, M. (2021). Labour market integration of refugee health professionals in Germany: Challenges and strategies. International Migration, 59, 105-126. https://doi.org/10.1111/imig.12752.

Korac, M. (2003). The lack of integration policy and experiences of settlement: A case study of refugees in Rome. Journal of Refugee Studies, 16(4), 398-421.

Korteweg, A. C. (2017). The failures of 'immigrant integration': The gendered racialized production of non-belonging. Migration Studies, 5, 428-444. https://doi.org/10.1093/migration/mnx025. 
Lee, E. S., Szkudlarek, B., Nguyen, D. C., \& Nardon, L. (2020). Unveiling the canvas ceiling: A multidisciplinary literature review of refugee employment and workforce integration. International Journal of Management Reviews, 22, 193-216. https://doi.org/10.1111/ijmr.12222.

Lillevik, R., \&Tyldum, G. (2018). En mulighet for kvalifisering: Brukerundersøkelse blant deltakere i introduksjonsprogrammet. Fafo-rapport 2018:35. Oslo: Fafo.

Ludwig, B. (2016). "Wiping the refugee dust from my feet": Advantages and burdens of refugee status and the refugee label. International Migration, 54, 5-18. https://doi.org/10.1111/imig.12111.

Maletzky de García, M. (2021). Bridging the state and market logics of refugee labour market inclusion: A comparative study on the inclusion activities of German professional chambers. Comparative Migration Studies, 9, 1-20. https:// doi.org/10.1186/s40878-021-00232-6.

Moncrieffe, J. (2007). Introduction: Labelling, power and accountability: How and why'our' categories matter. In J. Moncrieffe \& R. Eyben (Eds.), The power of labelling: How people are categorized and why it matters (pp. 1-16). London: Earthscan.

Mozetič, K. (2018). Being highly skilled and a refugee: Self-perceptions of non-European physicians in Sweden. Refugee Survey Quarterly, 37, 231-251. https://doi.org/10.1093/rsq/hdy001.

Mozetič, K. (2021). Cartographers of their futures: The formation of occupational aspirations of highly educated refugees in Malmö and Munich. International Migration, 59, 127-140. https://doi.org/10.1111/imig.12799.

Nardon, L., Zhang, H., Szkudlarek, B., \& Gulanowski, D. (2021). Identity work in refugee workforce integration: The role of newcomer support organizations. Human Relations, 74, 1994-2020. https://doi.org/10.1177/0018726720949630.

Parzer, M. (2021). Double burden of representation: How ethnic and refugee categorisation shapes Syrian migrants' artistic practices in Austria. Journal of Ethnic and Migration Studies, 47, 2459-2476. https://doi.org/10.1080/1369183X. 2020.1826297.

Phillimore, J. (2021). Refugee-integration-opportunity structures: Shifting the focus from refugees to context. Journal of Refugee Studies, 34, 1946-1966. https://doi.org/10.1093/jrs/feaa012.

Rytter, M. (2018). Made in Denmark: Refugees, integration and the self-dependent society. Anthropology Today, 34, 12-14. https://doi.org/10.1111/1467-8322.12433.

Rytter, M. (2019). Writing against integration: Danish imaginaries of culture, race and belonging. Ethnos, 84, 678-697. https://doi.org/10.1080/00141844.2018.1458745.

Saldaña, J. (2009). The coding manual for qualitative researchers. Los Angeles: SAGE.

Schinkel, W. (2018). Against "immigrant integration": For an end to neocolonial knowledge production. Comparative Migration Studies, 6, 1-17. https://doi.org/10.1186/s40878-018-0095-1.

Spehar, A. (2021). Navigating institutions for integration: Perceived institutional barriers of access to the labour market among refugee women in Sweden. Journal of Refugee Studies, 1-19. https://doi.org/10.1093/jrs/feaa140.

Valenta, M., \& Bunar, N. (2010). State assisted integration: Refugee integration policies in Scandinavian welfare states: The Swedish and Norwegian experience. Journal of Refugee Studies, 23, 463-483. https://doi.org/10.1093/js/feg028.

Wehrle, K., Klehe, U.-C., Kira, M., \& Zikic, J. (2018). Can I come as I am?: Refugees'vocational identity threats, coping, and growth. Journal of Vocational Behavior, 105, 83-101. https://doi.org/10.1016/j.jvb.2017.10.010.

Willott, J., \& Stevenson, J. (2013). Attitudes to employment of professionally qualified refugees in the United Kingdom. International Migration, 51, 120-132. https://doi.org/10.1111/imig.12038.

Zetter, R. (1991). Labelling refugees: Forming and transforming a bureaucratic identity. Journal of Refugee Studies, 4(1), 39-62.

\section{Publisher's Note}

Springer Nature remains neutral with regard to jurisdictional claims in published maps and institutional affiliations.

\section{Submit your manuscript to a SpringerOpen ${ }^{\circ}$ journal and benefit from:}

- Convenient online submission

- Rigorous peer review

- Open access: articles freely available online

- High visibility within the field

- Retaining the copyright to your article

Submit your next manuscript at $\boldsymbol{\nabla}$ springeropen.com 